\title{
Research on the Sports Talents Training Model in Colleges and Universities
}

\author{
Huang Tao \\ Sports Department of Taishan University, Taian Shandong 271000, China
}

Keywords: Sports specialty of colleges, talents training, model.

\begin{abstract}
Since the reform and opening-up policy, China has entered into a new era and various undertakings have acquired rapid development. And it has been difficult for traditional education model to adapt to the specific requirements of educational modernization in the new era as the market economy is becoming increasingly mature. College education plays a significant role in Chinese current education system, and it has a rather positive impact on training modern new-type talents. And ever since the new century, Chinese sports cause development has entered a new period, and our country also has achieved the perfect transformation from "a giant sports nation" to "a powerful sports nation", which has put forward various new requirements for our sports talents. Based on this, the paper analyzed the problems of sports talents training in the colleges and universities under the new era and made the discussion with the corresponding model.
\end{abstract}

\section{Introduction}

Along with the development of Chinese economy society, various undertakings of our country have made dramatic progress and China has entered a new stage of the transformation from "a giant nation" to "a powerful nation". And it plays a positive role in enhancing the comprehensive competitiveness as a vital component of "the path to a stronger China". Chinese sports cause has entered a stage with rapid development ever since the raising of "national fitness". In spite of the rapid development, traditional talents training model still are adopted, which is not only bad for the modern sports talents training of our country but also the achievement of transforming from "a giant sports nation" to "a powerful sports nation". Therefore, colleges and universities should combine with the practical condition of current Chinese sports development, positively change traditional talents training model and create the path of talents training to constantly satisfy the new requirements for sports talents under the new era when making the related training work.

\section{Positive meaning of sports talents training in colleges and universities}

\subsection{Beneficial to the development of Chinese sports cause}

As the significant places to train talents in our country, colleges take an irreplaceable part in the modern talents training. And Chinese various undertakings have made a great progress along with the rapid development of China's modernization. While the sports cause, as the vital component of the modernization construction of our country, plays a very significant role in manifesting comprehensive national power and enhancing the international competitiveness. So doing well in the sports talents training of colleges and constantly transmitting lots of sports talents with high quality for our country and society exert a very positive impact on the enhancement of Chinese sports development level and the promotion of the development of Chinese sports cause.

\subsection{Good for the promotion of students' comprehensive abilities}

There are many aspects of students' comprehensive abilities, and the degree of sports quality directly influences the promotion of students' comprehensive abilities. As the indispensable subject in the current college education, sports is of great significance to the assessment of comprehensive abilities for the students with various majors. Therefore, doing well in the talents training of sports departments in colleges and universities has a very positive effect on enhancing the comprehensive abilities of students. 


\subsection{In favor of strengthening the talents training level in colleges and universities}

The increasing development of modern education also has put forward new requirements for the colleges talents training, and traditional talents training model is difficult to satisfy with the talents demand of real society. So only the constant innovation of talents training model in colleges and universities can cultivate more excellent talent for our country. And sports talents training in colleges, as one part of college personnel training, is having a positive effect on pushing the enhancement of talents training in colleges. Doing well in the sports talents training in colleges and universities can provide more advanced experience for the talents training of other subjects, having a profound influence on the enhancement of talents training level in the whole colleges.

\section{Existing problems in the sports talents training model of colleges and universities}

\subsection{Rather low quality of sports talents training in colleges and universities}

Sports talents training in colleges and universities is related with the development and progress of national sports undertaking, which is helpful to achieve the perfect transformation from "a giant sports nation" to "a powerful sports nation". The increasing improvement of Chinese modern teaching model also leads to the gradually systematic and scientific college sports education. Even though the current college sports speciality setup is more specific and detailed, the teaching quality in the practical teaching process fail to obtain the real enhancement. The reason is that students have various levels and professional teaching staff exist some shortcomings in the practical talents training process, even though the objects of sports professional training in colleges are increasing annually with the increasing development of colleges and universities, which leads to the rather low quality of current college sports talents training. Besides, the professional comprehensive ability of sports talents in Chinese colleges have declined year by year with the gradual enrollment expansion of colleges and universities.

\subsection{Traditional concept and model of sports talents training in colleges and universities}

For a long time, Chinese college sports education has inherited a conventional and intrinsic model for the talents training, as a result, it is hard to meet with the demand of current China for the sports talents training in colleges. The increasing modernization of our country has put forward higher requirement for the comprehensive qualities of talents, however, the main education model and concept still remain the phrase of traditional "cramming method" when colleges are training sports talents. That is, teachers teach while students learn, and the whole teaching efficiency is rather low. Besides, it has not obvious effect on practical talents training, leading to the inferior ability of Chinese sports talents to adapt to society as well as the phenomenon of insufficient development strength. 1.Sports talents training in colleges and universities failed to combine with social development

In the current sports talents training in colleges and universities, the main model regards the sports education as the principal part and the sports teacher training as the main teaching objective, oriented with the courses of sports major. Such closed talents training model is usually equipped with very systematic course setting and rather clear teaching objective, also little referring to other subjects, which is of very positive meaning to training professional workers of sports education. However, with the social development and process, the new requirement for the comprehensive qualities of sports talents have been put forward, so the existing training model is hard to satisfy with the demand of society for sports talents in the new stage.

\section{Discussion of the sports talents training model of colleges and universities}

\subsection{Formulate scientific teaching plan and enhance specific teaching level}

Nowadays, there are many colleges setting the sports major in our country, so every college is supposed to formulate the specific and scientific teaching plan according to the practical conditions of students to increasingly enhance the sports education professional level and explore a set of systematic talents training model on this basis. In the practical teaching process, colleges can start from the following aspects to formulate scientific teaching plan and enhance professional teaching level. Firstly, each college should formulate the scientific teaching plan according to the practical 
condition of sunders and development reality of colleges, for instance, those colleges with better teaching conditions should start from the enhancement of students' comprehensive abilities and train sports talents through the combination of various teaching methods; while those colleges with inferior teaching conditions can start form the enhancement of students' sports competitive ability and professional knowledge, besides, encouraging students to make the continuing education to strengthen the comprehensive abilities of students; secondly, continually enhancing the professional teaching level by means of referring to the advanced sports education experience at home and abroad so as to gradually enrich their own teaching methods and enhance the class teaching efficiency and professional teaching level.

\subsection{Change teaching methods and optimize the teaching model}

The increasingly deepening reform of Chinese new course education and quality education have put forward new requirements for the current college sports talents training model. Traditional teaching methods exist certain limitations on enhancing the innovative ability and comprehensive quality of students, so the practical sports talents training should be based on the new course reform and quality education requirements and change teaching methods, optimize teaching model and enhance the innovative ability and comprehensive quality of students on this basis. At first, teachers should reform the traditional teaching methods, abandon the conventional inoculated teaching methods and constantly increase students' participation with sports education courses by means of combining the game with sports teaching or sports dance with sports teaching. Such methods can not only relieve the tedious degree of sports class, but also strengthen students' participation with sports courses, which exert a very positive impact on enhancing the teaching efficiency of sports class and teaching level of sports talents.

\subsection{Optimize the course setup and enrich teaching contents}

Even though the current sports teaching courses in Chinese colleges have greatly improved, for instance, students can autonomously choose optional courses to learn. However, there are rather few courses involved in these optional courses, which cannot radically change the current college sports talents training model. Therefore, in the practical college sports talents training, to truly meet the demands of the modern society for the cultivation of sports talents needs the positive course setting optimization, gradual teaching contents enrichment. And it can make gradual exploration on this basis and form a systematic talents training system with the practical conditions. Colleges and universities should actively comply with the trend of era development, fully consider the knowledge level and comprehensive ability of students, optimize the course setting and gradually enrich teaching contents, change single knowledge education structure system and combine with the related subjects. For example, the principal course setup in the social sports teaching should be oriented with kinesiology, somatology and sociology, but the rather simple course setting leads to the relatively scattered knowledge of this major, which is hard to meet the demand of modern society for social sports talents. The optimization of course setting and course structure and combination of modern curriculum theory with teaching theory have a very positive influence on enhancing the comprehensive ability of students.

\subsection{Combine the sports teaching with social development}

In the college sports talents training, the rather heavy problem is the deviation of sports teaching from course practice. Colleges, as the important place for the current modern new-type talents training, have an enormous effect on the social talents transportation. However, the current college talents training is a rather closed education model, and although such model is extraordinary for training sports education workers, it exists certain shortcoming on training the comprehensive sports talents in the new era. Therefore, the college sports talents training should be closely combined with social development and know the social development dynamic, besides, formulate the corresponding talents training plan and implement it according to the social development. And colleges are supposed to timely focus on the social development dynamic, understand the related policies of our country and constantly innovate the training model in the sports talents teaching and regard the overall talents meeting with the social development as the basic objective of talents training to enhance the comprehensive level of sports talents. What should be highlighted is that the practical condition of 
college development is supposed to be combined and a set of new model meeting the current sports talents training should be explored when colleges are formulating the talents training plan.

\subsection{Enhance the comprehensive quality of sports teachers}

College teachers play a very positive role in the sports talents training, and the comprehensive quality level of teachers directly influence the quality of sports talents training. Traditional sports talents training model is oriented with the cramming method to make sports comprehensive quality training. And it is proved that such teaching effect is very little and doesn't have especially obvious meaning on college sports talents training. Therefore, only by the continual enhancement on the comprehensive ability of teachers can more new-type sports talents meeting with social demand be trained in the practical teaching process. College sports teachers should constantly learn the new knowledge, keep pace with the times, closely combine with the times, always make themselves walk on the first line of health and activity, enhance their own sports education ability and work hard to strengthen the comprehensive quality, which can truly train the comprehensive sports talents meeting with the requirements of new era.

\subsection{Optimize the selection model and enrollment scale and strengthen the enrollment quality}

Along with the increasing enrollment expansion of Chinese colleges in recent years, the student sources in our country are gradually bigger. Many sports institutes also make the selection of sports talents with the help of enrollment expansion. Even if the enrollment expansion can make our college specialty scale get the unprecedented development and the number of college students have exceeded the demand of society for sports talents, the various students sources result in the uneven enrollment quality. So the college sports talents training didn't get a good development. On the contrary, the participation of many students with inferior culture class grades in the sports talents training plan leads to the not ideal effect of Chinese sports cause development. So colleges should constantly optimize the selection model and enrollment quality, strengthen the enrollment quality and start from the source to enhance the training level of college sports talents when they are enrolling the sports talents.

Ever since the implementation of national fitness policy, our sports cause development has entered a new phrase. And sports cause, as the principal component of realizing the great rejuvenation of the Chinese nation, plays a very positive role in enhancing the national physical health and competitiveness spirit. Social development has higher requirements for sports talents, but there still exist various problems in the current college sports talents training. And if colleges want to strengthen the college sports talents training level, constantly transport sports talents with high quality and truly realize the perfect transformation from "a giant sports nation" to "a powerful sports nation".

\section{References}

[1]Pei Yang. Analysis of the Sports Talents Training Model in Chinese Colleges and Universities[J]. Economic Research Guide,2017(06):129-130.

[2]Feiwei Yan. Research on the Sports Talents Demand and Training Model in Chinese Colleges and Universities under the New Circumstance[J]. Contemporary Sports Technology, 2016, 6(15): 111112.

[3]Wei Wang, Jing Wang. Research on the Social Sports Talents Training Model in Common Chinese Colleges[J]. Popular Science (science education),2016(01):142.

[4]Yanmiao Liu. Research on the Sports Talents Training Problems and Solutions in Colleges and Universities[J]. Technology Wind,2015(14):230.

[5]Fan Zhang. Research on the Sports Professionals Training Model in Colleges and Universities[J]. Knowledge Window (Teacher Edition),2015(01):6-7.

[6]Hong Ren. Discussion of the Sports Talents Training Model in Chinese Colleges and Universities[J].Boxing (Sports Forum),2013,5(08):31-32+45. 